Whitehall urged

ThE UK Agricultural Research Council is now poised to gain control of $£ 2 \frac{1}{2}$ million of its funds previously tied to work commissioned by the Ministry of Agriculture, Fisheries and Food (MAFF). And this desire for greater freedom from the commitments of the Rothschild reorganisation of research has been reinforced by a plea from the Medical Research Council that Department of Health and Social Security control of its funds be reduced.

Both developments were revealed following last week's publication of the minutes of meetings of the House of Commons public accounts committee. In the case of the ARC it was stated that a review had been carried out by the MAFF and the Department of Education and Science under the previous government and this had investigated charges made by the ARC for use of its facilities. In particular, it was felt that more money should be paid by the MAFF for superannuation of staff carrying out its work and also for some capital costs. The full charges amounted to about $£ 2 \frac{1}{2}$ million and it is now known that the Ministry has decided to pay this figure.

Although the MAFF will still control $54 \%$ of the ARC's budget, which last year totalled $£ 45.6$ million, it will now find $£ 2 \frac{1}{2}$ million of its money earmarked for staff and other costs. This will free an equal sum for direct use by the council, which is likely to spend it on priority areas such as the genetic manipulation of plants with the aim of introducing new characteristics in crops.

However, the agreement to charge full economic costing for ARC facilities still has to be confirmed by the new Conservative administration, and this decision is expected shortly. Even when agreed, the effect will not be immediate, as many MAFF projects are being funded over long periods and there is no question of them being abandoned. But in the long term this financial reallocation will certainly give the ARC far greater flexibility in its undertakings.

In his plea to the committee, Dr James Gowans, the secretary of the MRC, said the transfer of its funds to DHSS control represented a vulnerable area in the council's $£ 60$ million budget: "It is vulnerable because the rules say the government departments are expected to spend the transferred funds with particular councils, but they do not have to."

He described the present arrangement as not being ideal-a dissatisfaction that stems, in part, from the 1976 cutbacks which resulted in the DHSS suddenly reducing its funding of

\title{
to relax grip on research funds
}

the council by $10 \%$. "I should like to enter a plea that the MRC feels a little uneasy about the large chunks of its funds which could with political change be either decreased or might conceivably disappear. In fact, I should like to see in the long term the fraction of my council's total money, which is free money, increase-to give us greater stability and flexibility", he told the committee.

Dr Gowans said there were particular difficulties in trying to direct biomedical research through departmental contracts. One problem stemmed from the MRC's need to supervise all research, from basic to applied.

"In cancer, for example, we would

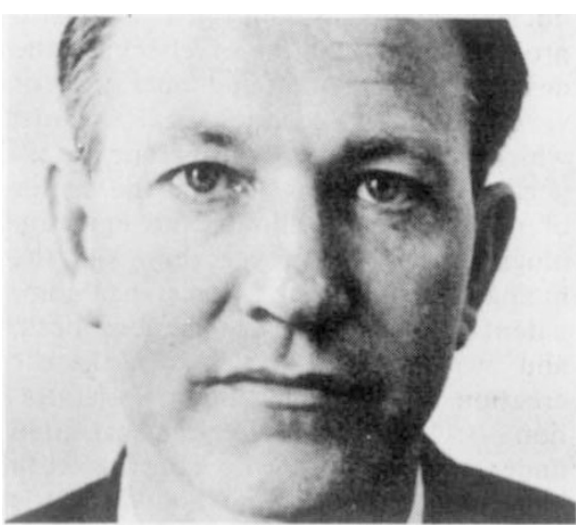

James Gowans, MRC: "vulnerable"

consider it essential to start with basic molecular biology and go right through to trials of new chemicals and radiation therapies", he added. It was of no use to pick a small fraction of a programme and concentrate only on that aspect.

"The other point is that if one looks back at the history of medical discovery, one finds that the key discoveries have all been made by accident", he stated. This also made it difficult to commission effective pieces of research and Dr Gowans indicated that he would prefer a system of saturating the very best talent with funds, although this would be hard to justify in times of financial stringency when many workers were competing for limited funds.

However, in his report to the committee, Sir James Hamilton, permanent secretary at the Department of Education and Science (which controls the major portion of the MRC's budget) said it would be wrong to suggest the idea of the customer-contractor relationship had failed-although he revealed that the DHSS-MRC relationship will be reviewed this autumn. This is to ensure basic objectives are being met in terms of scientific and financial accountability and are not being unnecessarily burdensome in bureaucratic terms.

Robin McKie

\section{WHO lays down safety guidelines}

THE World Health Organisation is making progress with its attempt to lay down guidelines on occupational exposure to toxic substances. A meeting in Geneva this month agreed on a methodology for arriving at permissible levels of exposure to four heavy metals -cadmium, lead, manganese and mercury.

The first step is to examine all the available medical and scientific information, followed by the decision on what degree of risk can be tolerated. Degree of risk has to be decided at national level, partly because circumstances differ in some countries. For example, in the tropics, industrial workers may also be exposed to endemic diseases affecting the kidneys, liver or lungs. The acceptable level of metals toxicity affecting the same organs would therefore have to be much lower there than in northern industrialised countries.

The meeting made a breakthrough with agreement between the US and USSR on what should be the actual basis for exposure. The Soviets are considering switching to the American system of time-weighted exposure and abandoning their previous "maximum exposure" basis. There has also been agreement on the principle of adverse health effects" for the four metals under consideration. Two criteria have been laid down: (a) is the effect reversible or not? (b) are compensatory mechanisms in the body impaired? From this it is possible to define the effects of each substance on an agreed "target organ".

Finally, the Geneva meeting agreed on permissible levels for each metal, both "biological levels" in the person affected and atmospheric levels in the place of work or in the immediate vicinity of a plant such as a lead smelter.

The need for guidelines such as these was because of the wide discrepancies in permissible levels between various industrialised countries and the feeling that guidance would help Third World countries moving into industrialisation. Previous attempts to recommend levels of toxicity through the International Labour Organisation have tended to be blocked by employers pressure groups. The WHO approach was specifically medical and scientific, but it is understood there were, nonetheless, messages of strong disapproval from a number of industrial firms.

Peter Collins 